\title{
Lenguaje e Historia: A propósito de la controversia entre Koselleck y Gadamer
}

\author{
JUAN LUIS JIMÉNEZ RUIZ \\ (Universidad de Alicante)
}

Al cumplir H. G. Gadamer ochenta años, la Academia de las Ciencias de Heidelberg y el departamento de Filosofía de la Universidad de Heidelberg realizaron un acto solemne de celebración académica en el que R. Koselleck pronunció una conferencia sobre «Histórica y hermenéutica» a la que Gadamer contestó, a continuación, con su interesante reflexión sobre «Histórica y lenguaje: una respuesta». Estábamos en el año 1985; concretamente el día 16 de febrero.

A partir de entonces, la sección histórico-filosófica de la mencionada Academia manifestó su intención de publicar ambas conferencias. Sin embargo, el texto de Koselleck se publicó a los dos años, concretamente en 1987, en Heidelberg, y el de Gadamer en 1993, en Tubinga, constituyendo dos de los pilares fundamentales de la reflexión teórica sobre la historia y el lenguaje ${ }^{1}$.

Por ello, la importancia del texto que sirve de base a esta reflexión consiste en presentar por primera vez al público de habla hispana de forma unitaria tanto la conferencia de Koselleck como la respuesta de Gadamer, en un texto titulado Historia $y$ hermenéutica, precedido por la interesante introducción en la que José Luis Villacañas y Faustino Oncina acercan al lector a la comprensión de los diversos sentidos que puede presentar la noción de «historia conceptual» para comprender el

\footnotetext{
${ }^{1}$ Una visión general sobre los grandes problemas teóricos de la Historia, su Filosofía e Historiografía puede verse en Burke, 1993; Cruz, 1991; Montanari et alii, 1993; Mate, 1993; Ruiz Torres, 1993; entre otros.
} 
trasfondo de la controversia entre Koselleck y Gadamer, problemática sobre la que gira el contenido del libro².

En palabras de los editores:

«...la historia conceptual... como instrumento metódico autónomo para la teoría filosófica... se integra en la filosofía, concebida como una comprensión racional del mundo natural y social, al acreditar la eficacia histórica de los conceptos y aquilatar su uso en un contexto significativo» (pág. 9).

De ahí la importante relación entre historia y lenguaje, sin los cuales no podríamos comprender ni al ser humano ni tampoco la realidad social que le rodea.

Ello justifica que la reflexión koselleckiana sobre las tensiones entre la «doctrina de la historia» y la «doctrina de la comprensión» así como su propuesta de negación a que la primera — la historia - sea absorbida por la segunda — la hermenéutica-, encuentre en la ontología universal del lenguaje gadameriana su respuesta teórica.

Y aunque quizá sea desde el punto de vista lingüístico la aportación de Gadamer la que más nos interesa, puesto que la figura de H. G. Gadamer, filósofo y filólogo, no es excesivamente conocida en España ${ }^{3}$, por lo menos directamente ${ }^{4}$; vamos a comenzar señalando primeramente los principales puntos de la reflexión koselleckiana.

\section{La reflexión de Koselleck sobre el lenguaje y la historia}

Koselleck (1997: 67-94) desarrolla en este trabajo la problemática central de su planteamiento científico: la relación entre la hermenéutica y la historia ${ }^{5}$.

Para él ${ }^{6}$, el fenómeno de la comprensión está vinculado al tiempo entendido no sólo como situación temporal o espíritu de una época sino también como maduración de quien llega a ser consciente de su tiempo comprendiéndolo.

\footnotetext{
${ }^{2}$ R. Koselleck y H. G. Gadamer: Historia y hermenéutica, Introducción de J. L. Villacañas y F. Oncina, Paidós, I.C.E. Universidad Autónoma de Barcelona, Barcelona, 1997, 125 págs.

${ }^{3}$ De hecho, es de todos conocida la neohermenéutica francesa de Ricoeur, por poner un caso, quien la confronta con el estructuralismo, el existencialismo y el psicoanálisis, proponiendo una vía de salida del oscuro idealismo en el que se transforma al final la fenomenología hacia el mundo real en el que cada vez tiene más valor lo trascendente; cf. Fidalgo, 1996; Garrido Domínguez, 1996: 219-238. Asimismo, es interesante la comparación que López Sáenz (1996: 151-172; 1997: 215-242) realiza entre las teorías de la interpretación de P. Ricoeur y H. G. Gadamer.

${ }^{4}$ Lo es, en todo caso, a través de las reflexiones de E. Lledó, discípulo directo de Gadamer y, como éste, filósofo y filólogo.

${ }^{5}$ La razón es obvia puesto que, como reconoce Lozano (1987: 11-12), no puede hablarse con rigor de un solo discurso histórico al tener cada época criterios diferentes y enfrentados que determinan el propio quehacer historiográfico con un sesgo hermenéutico específico.
} 
El problema para Koselleck consiste en saber si la Historia —al plasmarse gracias al lenguaje en textos- puede o no sustraerse del cosmos hermenéutico inherente a todo acto linguístico. Por ello, si existen condiciones extralingüísticas o prelinguíisticas que amplían las condiciones de la posibilidad de una historia en el lenguaje y en los textos:

«Si existen tales presupuestos de la historia que no se agotan en el lenguaje ni son remitidos a textos, entonces la Histórica debería tener desde el punto de vista epistemológico, un status que le impida ser tratada como un subcaso de la hermenéutica. Ésta es la tesis que quiero fundamentar» (pág. 69).

Para ello, Koselleck estructura la reflexión para demostrar esta tesis en dos grandes bloques en los que, primero, presenta una historia basada en características prelingüísticas a partir de la lectura de $E l$ ser y el tiempo heideggeriano ${ }^{7}$; y segundo, confronta los resultados anteriores con las posiciones de Gadamer en su libro Verdady método ${ }^{8}$.

Al comienzo del trabajo, Koselleck presenta las bases de su concepción sobre la Histórica como «doctrina de las condiciones de posibilidad de las historias», apuntando tanto a los nexos entre los acontecimientos como a la representación de los mismos.

A continuación reflexiona sobre las propuestas de Heidegger, que considera insuficientes para desarrollar una Histórica que logre derivar también las condiciones de posibilidad de historias a partir de la determinación fundamental de la finitud y la historicidad. La razón estriba en que Heidegger se quedó sólo con la categoría de la historicidad, sin ayudar a fundamentar trascendentalmente la diversidad de las historias reales.

Como complemento metodológico nos propone cinco categorías con las que poder realizar una correcta tematización de la estructura temporal de las todas las posibles historias.

\footnotetext{
${ }^{6}$ Una visión general sobre sus perspectivas, reflexiones, así como aportaciones a la metahistoria y filosofía de la historia puede verse en Koselleck, 1993.

${ }^{7}$ En esta obra, Heidegger (1993) nos presenta un análisis exhaustivo del proceso de la comprensión, considerándolo como el principal núcleo constitutivo existencial del ser en el mundo.

${ }^{8}$ En él, Gadamer (1991) reivindica un concepto de verdad para las ciencias del espíritu en el ámbito, siempre lingüístico, de la comprensión. Para explicitar su concepción de la verdad nos expone sus reflexiones sobre la relación entre lenguaje y mundo. Al respecto es interesante Vilana Taix, 1995: 261271.
} 


\section{la}

Añade, en primer lugar, a la categoría heideggeriana de «precursar la muerte» como elemento principal para posibilitar las historias, la categoría de «poder matar», puesto que:

«Sin la capacidad de poder matar a sus semejantes, sin la capacidad de poder abreviar violentamente el lapso posible de vida de cada uno de los otros, no existirían las historias que todos conocemos» (pág. 75).

Se trata, en definitiva, de la antítesis entre el «tener que morir» y el «poder matar» como única vía para la supervivencia, la que constituye el primer determinante de la historia misma propuesto por Koselleck.

$1 b$

La siguiente oposición es la de «amigo» frente a «enemigo», categorías trascendentales que se manifiestan sobre el trasfondo de todas las historias de autoorganización humana.

Como reconoce el propio Koselleck (1997: 76), se trata de una oposición formal abierta a toda atribución de contenido, puesto que «el ser para la muerte puede quedar superado en todo instante por el ser para matar».

$$
l c
$$

La tercera oposición es de carácter más universal. Está atravesada por el eje de los polos «interior»y «exterior», que constituyen la auténtica espacialidad histórica?.

Puesto que, desde una perspectiva diacrónica, varían naturalmente los espacios así como su densidad y magnitud, también varían los conflictos desencadenados por trazados fronterizos.

Por ello, las épocas de la historia pueden definirse — desde el punto de vista del contenido- según las correlaciones entre lo «interno» y lo «externo», entre lo «público» y lo «secreto», ya que estructuran las condiciones de todas las historias posibles.

\footnotetext{
${ }^{9}$ Para Heidegger, el Dasein, en cuanto existencia, tiene un carácter espacial que «tiene también entre otras posibilidades, la de un espacial 'pasar por encima' de una barrera o abismo espacial» (Heidegger, 1975: 23) que ayudará a configurar la historia.
} 


\section{$1 d$}

Diferencia, a continuación, entre el «estar arrojado» o nacimiento con que se inicia la vida $\mathrm{y}$, por tanto, también la muerte y la «generatividad» como determinación generacional entre padres e hijos:

«Los cambios y choques generacionales son constitutivos por antonomasia del horizonte temporal finito, por cuyo respectivo desplazamiento y solapamiento generativo consisten las historias» (pág. 82).

Estas historias factuales pueden ser, pues, resultado de un consenso entre las distintas generaciones o de una fractura entre ellas.

le

Finalmente, Koselleck añade al análisis de la finitud mediante el cual Heidegger puso de relieve la importancia de la temporalidad y de la historicidad como motores de la historia en general, las categorías de «amo» y «esclavo».

Se trata de relaciones jerárquicas sin las cuales tampoco serían posibles las historias.

En resumidas cuentas, la confluencia entre los cinco pares antitéticos estudiados por Koselleck que preparan la Histórica se encuentra en las determinaciones existenciarias, en su carácter categórico trascendental que posibilita las historias.

Permiten pues, la ilustración de las estructuras de la finitud, puesto que:

«...por excluirse mutuamente, evocan tensiones temporales necesarias entre las unidades de acción y dentro de éstas. Las historias acontecen sólo porque las posibilidades inscritas en ellas superan con creces las que después se pueden cumplir» (pág. 85).

Para la realización en el tiempo son necesarias estas determinaciones antitéticas que expresan la finitud temporal en la que surgen las tensiones y conflictos que posibilitarán el desarrollo de las historias.

A continuación, Koselleck (1997: 86-94) confronta las reflexiones precedentes con las posiciones de Gadamer, introduciendo la categoría que más nos interesa: la «lingüisticidad» en el mundo de la existencia humana. Responde al hecho de que toda 
existencia está orientada a la comprensión del mundo, que es aprehendido y constituido lingüísticamente en ese mismo acto.

De ahí que la hermenéutica vaya unida a la posibilidad de su expresión lingüística $y$, por tanto, sea histórica, siendo entendida por Koselleck como la «doctrina de la inserción existencial en lo que se puede denominar historia, posibilitada y transmitida lingüísticamente» (pág. 86). De ahí el rango histórico de toda hermenéutica.

Seguidamente, Koselleck reflexiona sobre el status lingüístico de las categorías que ha empleado en la descripción de las condiciones trascendentales de las posibles historias, llegando a la conclusión de que la linguiisticidad no ha conseguido convertir a la Histórica en un subcaso de la Hermenéutica.

«no basta con que el origen de la teoría histórica sea demostrable linguísticamente o con que esta teoría pueda ser concebida como una respuesta linguística a una pregunta previamente dada.

Para la tarea científica de una Histórica importa lo que es capaz de ofrecer analíticamente a fin de encontrar un orden racional en el caos de hallazgos históricos o de la presencia histórica» (pág. 88).

Para demostrar su reflexión parte de dos tesis gadamerianas.

\section{$3 a$}

La primera es la que afirma que, aunque nuestra experiencia del mundo es posibilitada y mediada lingüísticamente, nunca es sólo un proceso lingüístico ni se agota en el lenguaje. Lo que significa que la hermenéutica encuentra su legitimación final en la experiencia de la historia, ya que lo que importa es - aunque expresado linguísticamente - el objeto extralingüístico.

\section{$3 b$}

La segunda tesis sostiene que entre las ciencias interpretativas de textos, la ciencia histórica posee un rango que representa casi la superación de todo proceder hermenéutico. Frente al filólogo, que presta más atención a la forma lingüística de expresar el objeto en el texto que al objeto mismo, el historiador se sirve del texto como testimonio para averiguar una realidad que está fuera de él.

«Por consiguiente, debemos diferenciar, al menos metódicamente entre orientar la comprensión hacia los textos, a fin de entender su enunciación de un estado de cosas, e inquirir algo que se filtra sin quererlo a través de los textos y que sólo más tarde resulta ser la verdad histórica» (pág. 93). 
Por ello, para Koselleck, hay procesos históricos que no pueden ser comprendidos e interpretados linguísticamente y que sólo en la Histórica, como disciplina que va más allá de lo lingüístico, pueden tener cabida.

\section{La reflexión de Gadamer sobre el lenguaje y la historia}

Podemos considerar a H. G. Gadamer como el padre de la hermenéutica actual ${ }^{10}$; fue defensor de la escuela de Heidegger, profesor de la Universidad de Heidelberg, director de la revista Philosophische Runschau y presidente de Congreso alemán de Filosofía.

Su reflexión consiguió trasladar la hermenéutica desde la Gnoseología a la Ontología del lenguaje, inclinando la balanza del lado de la energeia humboldtiana (o lenguaje como energía del espíritu subjetivo humano) frente al ergon (o lenguaje como obra material o formal del hombre ${ }^{11}$. Por ello, toda interpretación debe serlo del lenguaje, ya que éste es el único medio para que se produzca el entendimiento y, para Gadamer, el entendimiento es siempre interpretativo -incluido el explicativo o científico-naturalista—. Es lo que Gadamer denomina «lingüisticidad»:

«La lingüisticidad que la hermenéutica emplaza en el centro no es sólo la de los textos; por tal entiende igualmente la condición del ser fundamental de todo actuar y crear humanos [la cursiva es nuestra]» (pág. 104).

De ahí que el predominio linguístico ${ }^{12}$ deba abarcar incluso la tarea del historiador que, en el fondo no es otra que la de «comprender investigando ${ }^{13}$.

Esta comprensión - lingüística - que postula Gadamer reintegra la interpretación en la historia ya que posibilita no sólo la conexión entre la Historia y las restantes Ciencias Humanas y Sociales (González Wenceslao, 1996: 152) sino también la ubicación tanto del intérprete como del interpretado bajo el sentido que impone la

\footnotetext{
${ }^{\text {to }}$ Los fundamentos de su hermenéutica así como la evolución de la teoría de la interpretación de raíz gadameriana pueden verse en Esteban Ortega, 1996: 403-428; López Sáenz, 1997: 215-242; Ramos Requejo, 1995: 61-93; Revilla Guzmán, 1995: 171-188; Vilana Taix, 1995: 261-271; entre otros.

"De hecho, la hermenéutica constituye hoy en día la orientación que tiende a establecer —quizá como complemento necesario del pragmatismo positivista - el punto de vista más fecundo tanto en lo que respecta a la historiografía como a las restantes ciencias humanas (Jarque, 1994: 243).

${ }^{12}$ Utilizamos el término en el sentido crespillano de «categoría estática que indica el proceso rector por el que todo hecho humano se recubre de un matiz linguístico», cf. Crespillo, 1981: 25-31.

${ }^{13}$ Es el método postulado por Droysen para la investigación en las ciencias históricas, método que, basado en el entendimiento - Verstehen - se opone al de las ciencias naturales que se basa en la explicación -Erkeären-; cf. Droysen, 1983: 35.
} 
propia historia ${ }^{14}$, al ser la que primero interpreta los sentidos ocultos (Ortiz Osés, 1973: 60).

En palabras de Gadamer:

«la mirada de quien comprende sigue toda huella de sentido y busca siempre el sentido que le permite abrir constantemente en medio de la insensatez del acontecer y de la historia, algo parecido a horizontes de expectativas, de esperanza, de osadía y de no abyección» (pág. 100).

Quizá lo importante de todo ello esté en saber cuáles son las causas de esta actitud no sólo metodológica sino también existencial. La respuesta podría estar en los propios fundamentos internos de la hermenéutica trascendental del lenguaje defendida por Gadamer, que defiende la concepción del conocimiento como el reconocimiento «en lo otro, en lo otro de los hombres, en lo otro del acontecer» (pág. 105).

Esta reflexión linguística (paralela a la hermenéutica filosófica trascendental del conocimiento desarrollada por Dilthey o Heidegger ${ }^{15}$ ) fue comenzada por Platón en el Crátilo, recogida por el Nominalismo Medieval y el racionalismo cartesiano, y continuada en la Edad Moderna por Herder. El lenguaje no es un instrumento, sino que el acto de pensar mismo es un acto de lenguaje, y puesto que el hombre es un ser activo y con libertad de pensar, es una criatura de lenguaje ${ }^{16}$. Desde este punto de vista, el Lenguaje se convierte en el creador del hombre mismo, en la determinación de la energía del Espíritu.

Como hemos dicho, sus fundamentos pueden encontrarse en Schleiermacher, Dilthey y Heidegger ${ }^{17}$.

${ }^{14}$ Así, frente a concepciones reduccionistas de la historia, la hermenéutica gadameriana respeta la dialéctica entre historia y hermenéutica, dando un carácter prioritario a la apropiación no sólo del interpretado sino también —lo que es más importante- del interpretante; cf. López Sáenz, 1996: 151172 .

${ }^{15}$ De hecho, la estructura circular de la intelección humana - mostrada por el «círculo hermenéutico» heideggeriano (Heidegger, 1993) — basada en el hecho de que no podemos conocer un todo sin conocer alguna de sus partes, ni tampoco las partes como tales sin conocer el todo que determina sus funciones, ha sido recogida y sistematizada con detalle por Gadamer (1991: 227, 244 y ss., 331 y ss.). Al respecto es interesante la explicación de Santos (1995: 155-162) sobre la valoración gadameriana de los dos momentos del acto inicial de la comprensión histórica - como mutua interpelación entre intérprete y cosa-, a partir de la reflexión de Heidegger sobre el «círculo hermenéutico».

${ }^{16}$ De hecho, la dimensión hermenéutica del propio pensamiento, puesta de relicve por Gadamer y basada en la concepción platónico hegeliana, explicita la necesidad de reivindicar la dimensión ontológica de la memoria. Es la tesis que Esteban Ortega (1996: 403-428) desarrolla poniendo en relación las reflexiones gadamerianas con las de su discípulo E. Lledó.

${ }_{17}$ Concretamente en las obras completas de Schleiermacher, Sämmtliche werke, edición de L. Jonas, Berlín, 1835-1864, en las que expone sus reflexiones sobre los problemas de la interpretación; en el 
Para Schleiermacher la interpretación es la construcción de un entendimiento comparativo - propone lo que hay que entender como algo general, y encuentra to particular al compararlo con otros, entendidos desde la misma perspectiva general-y adivinatorio - mientras se transforma en el otro, intenta buscar inmediatamente lo individual-, puesto que todo discurso tiene una doble operación con la totalidad del lenguaje y con el pensamiento total de su autor. De esta manera, el comprender se refiere tanto al lenguaje, como interpretación gramatical, cuanto a los hechos mentales, como interpretación psicológica.

Ello exige una metodología que, en el caso schleiermachiano, es simpatética, puesto que considera la interpretación como la forma de llegar al otro para saberlo ${ }^{18}$.

En el fondo, como reconoce E. Lledó (1997: 45), Schleiermacher deja abierto el campo de la subjetividad interpretadora que, como en el caso de la del autor, es también histórica.

\section{6}

Desde la perspectiva de los valores y la dialéctica entre las ciencias de la Cultura o el Espíritu, Dilthey (1978) sostiene que el comprender es el encuentro entre un yo y un tú que forman parte de un todo histórico cultural, gracias a la posibilidad de la comunicación.

Con su reflexión, Dilthey ha trasladado a la hermenéutica actual problemáticas como las de la historicidad de la comprensión, la consideración de la posición histórica en el proceso de comprensión, el papel de la distancia histórica, la historia de los efectos, etc. (Szondi, 1997: 64).

El quehacer del hermeneuta es el quehacer del historiador y éste ha de revivir la vivencia que sustenta la objetivación del espíritu en la historia (Ortiz Osés, 1973: 5455). Se trata, pues, de una hermenéutica del entender humano como autocomprensión del hombre en su mundo ${ }^{19}$.

ensayo de Dilthey sobre la formación de la hermenéutica (Die Entstehung der Hermeneutik), publicado en 1900, en el que desarrolla su teoría de la comprensión histórica como fundamento de las ciencias del espíritu; y, finalmente, en la obra de Heidegger El Ser y el Tiempo (Sein und Zeit), publicada en 1927, en la que, como ya dijimos anteriormente, analiza la comprensión como elemento constitutivo existencial del ser en el mundo (Dasein).

${ }^{18}$ Hasta tal punto Schleiermacher insiste en la importancia del autor que afirma que para comprender un texto debemos no sólo entrar en la mente del autor sino también identificamos con él; ef. Bravo y Schökel, 1997: 27.

19 Tanto la hermenéutica metódica de Schleiermacher como las tipologías de las concepciones del mundo de Dilthey han estado en la base de las distintas formulaciones sobre la comprensión e interpretación. Una reflexión al respecto puede verse en Sánchez Meca, 1997: 41-54. 
Ic

Finalmente, Heidegger supera el romanticismo schleiermachiano y el historicismo diltheyano elaborando una ontología fenomenológica de carácter universal ${ }^{20}$. Sostiene que el lenguaje adquiere con la historia una determinada carga significativa que hay que descubrir. Por ello, la única solución consiste en trascender la realidad y hacer hablar al lenguaje en cuanto lenguaje para que, de esta manera, hombre y mundo puedan unirse (Lledó, 1970: 117 y ss.).

En este sentido, el entendimiento forma parte de la estructura misma del ser humano siendo, de esta manera, autocomprensión a partir del $\operatorname{ser}^{21}$. Esta comprensión se produce históricamente puesto que nuestro mundo histórico es una precondición de nuestra experiencia y, por tanto, forma parte de toda interpretación (Hirsch, 1997: 147).

Así, la hermenéutica tiene como objeto y sujeto a un tiempo el problema del comprender, comprensión entendida como una realización exegética del mundo (significación y sentido) a través del lenguaje (Ortiz Osés, 1986: 226-228).

Todas estas reflexiones constituyen la base de la obra fundamental de Gadamer Verdad y Método (Wahrheit und Methode), publicada en 1960, en la que nos presenta los principales pilares de la hermenéutica moderna. El Lenguaje es en ella el instrumento innato (Descartes) de la Razón que correlaciona mundo y hombre, como icono remitiendo a la experiencia del pasado, y como indicio a la del presente; no es ni una ideología (Weltanschauung) ni una concepción del mundo (Weltbild), sino el mundo intermedio mediador (Zwischenwelt) que permite el auténtico entendimiento (a la vez subjetivo y objetivo) de la realidad, realizado gracias a la fuerza del espíritu creador humano que se objetiva y autoencuentra de un modo individual y social a la vez, en el Lenguaje. Por ello, frente a la concepción positivista del Lenguaje como objeto mediador de la realidad inmediata, el Lenguaje aparece como sujeto constitutivo de la realidad mediata a la espera de ser aprehendido com ocategoría histórica:

\footnotetext{
${ }^{20}$ La estética del siglo XIX trata el arte en general como una actividad subjetiva, dejando en segundo lugar el examen profundo de la obra. Heidegger cambiará esto acercándose al texto como tema concreto de un análisis filosófico, realizando una auténtica ontología del arte. Al respecto es interesante Heidegger, 1982.

${ }^{21}$ Sobre la hermenéutica heideggeriana y sus consecuencias teóricas más relevantes puede verse Borges Duarte, 1995: 213-232.
} 
«Es reconocimiento de nosotros mismos y, por tnto, se adentra constantemente en la corriente de problemas que se nos impone como hombres... Esto debería recordarnos la caracterización aristotélica del lengujaje. No porque todo sea lenguaje. El lenguaje no habla de sí, sino de los que es o presumiblemente es. Pero, puesto que el lenguaje se orienta hacia lo abierto, hacia el todo... delinea el vasto horizonte del «ahí» de mundos humanos. Por eso escuchamos a quien narra historias» (pág. 106).

Por eso y porque nosotros, con nuestras historias, construimos una comunidad basada en lo que tiene sentido para nosotros. Esta historia es pues, sujeto de nuestra propia interpretación, lenguaje a contestar, diálogo por realizar ${ }^{22}$. Este diálogo es el que, precisamente, permitirá la comprensión del mundo en las diversas lenguas.

Con un título parecido ${ }^{23}$ se inicia el segundo trabajo de Gadamer con el que concluye el libro Historia y hermenéutica. Aquí se plantea una de las grandes problemáticas de la hermenéutica: la validez de la interpretación sobre el mundo, problemática relacionada directamente con la del entendimiento unívoco del mundo para lograr una auténtica comunicación integral (la diversidad de las lenguas).

\section{$3 a$}

A partir del texto bíblico sobre la Torre de Babel, Gadamer reflexiona sobre la esencia del lenguaje y el mundo llegando a la conclusión de que «el imponente esfuerzo de abstracción realizado por la humanidad mediante sus lenguas encierra un completo olvido del lenguaje» (pág. 112).

Será sólo a partir de la llustración cuando el lenguaje, en su diversidad y universalidad, entre a formar parte de la conciencia produciéndose un doble efecto: el giro hacia lo lingüístico (linguisticturn) con Wittgenstein, orientado al análisis de la forma en que hablamos al comunicarnos unos con otros, y, por otro lado, la transición del neokantismo a la fenomenología, concretada en el giro hermenéutico introducido por Heidegger ${ }^{24}$.

\footnotetext{
22 Sobre la concepción de la textualidad gadameriana y la importancia del diálogo en su hermenéutica es interesante Revilla Guzmán, 1995: 171-188.

${ }^{23}$ Se trata de la conferencia titulada «La diversidad de las lenguas y la comprensión del mundo» pronunciada dentro del programa de actividades del Studium generale de 1990 de la Universidad de Heidelberg.

${ }^{24}$ Como sostiene Borges Duarte (1995: 213-232), la importancia de Heidegger en la historia de la recepción de la Filosofía Crítica estriba en dar un nuevo sentido a las problemáticas kantianas desde el punto de vista fenomenológico.
} 
«Éste es el nuevo paso en el que nos encontramos: pensamos así el lenguaje como un estar de camino a lo común de unos con otros (ein unterwegs zum Miteinander) y no como una comunicación de hechos y estados de cosas a nuestra disposición» (pág. 116).

\section{$3 b$}

Por tanto, no se trata de comprender el mundo, puesto que comprender es entenderse en el mundo. Se trata, pues, de entenderse unos con otros, de entender al otro a partir de las lenguas.

Por ello, debe emplearse la verdadera productividad del lenguaje para entendernos, ya que, además de su concreción como un sistema de reglas, constituye la base social del pensamiento individual, formando parte tanto de la cultura — puesto que es un comportamiento humano aprendido sobre la base de la capacitación biológica del hombre - como de la estructura social - ya que permite la comunicación en el espacio y en el tiempo-.

«En esto consiste primordialmente hablar y la hermenéutica sirve para desarrollar la posibilidad de transmitir al otro lo que uno piensa de verdad y obtener de él la respuesta, la réplica de su modo de pensar» (pág. 122).

Se trata, por tanto, de alcanzar el entendimiento gracias al diálogo, lo que quiere decir que se entiende el mundo no como ser — definido en última instancia como idea - sino como lenguaje -definido en última instancia como comunicación(Ortiz Osés, 1973: 116).

\section{Corolario}

Finalmente, debemos coincidir con E. Lledó (1975), en el hecho de que el individuo es parte integradora de la historia puesto que el hombre hace la historia y la historia hace al hombre en un proceso de mutabilidad producido por el procedimiento de proyección de nuestra actividad y pensamientos en la naturaleza, la sociedad y la cultura.

La historia del hombre es, pues, la historia de sus realizaciones. Sin embargo, éstas no deben medirse en función de sus hechos sino de los sentidos de esos hechos. Es el carácter linguístico semántico de la historia, que permite la unión entre el hombre y la naturaleza y, por consiguiente, la auténtica historia signológica — no de hechos sino de signos-.

La razón no es otra que el gran apasionamiento que ha despertado siempre en el hombre la aprehensión de su propia memoria histórica. Para ello, lo importante es según Lledó (1997: 55): 
«...llegar a una praxis hermenéutica que, a pesar de su esencial historicidad, ofrezca a cada época, a cada momento de la temporalidad inmediata, el inconfundible sonido de la temporalidad mediata, de los textos, mediados, interferidos ya por el hilo del pasado que necesariamente lo enhebra».

Por ello, como ya tuvimos ocasión de expresar anteriormente (Jiménez Ruiz, 1996: 11), creemos que cualquier planteamiento histórico no puede ser otro que hermenéutico, pues consiste en trascender el presente para llegar al pasado (Hegel, 1974, 155). Sin embargo, frente a la narración de acontecimientos de lo que podría ser una historia arte y a la investigación de los mismos de lo que constituiría la historia ciencia, la hermenéutica evita la elección de ambos extremos (Pomian, 1984, 21 y ss.) y posibilita la adopción crítica de una actitud metodológica de acceso a los datos.

Sólo así se podrá profundizar en lo que White (1978) denominó «análisis de la estructura profunda de la imaginación histórica» y nosotros (Jiménez Ruiz, 1999: 164), historia como historia del lenguaje, abstracción geométrica que organiza «la flecha del tiempo» (Massuh, 1990) en el terreno lingüístico, mediante un ejercicio de reproducción del lenguaje sujeto en la lengua objeto.

La historia, pues, no es sólo la visión semántica de un orden que otorga significado a los momentos de la historia, sino que es también la aprehensión de la autoconsciencia de ese mismo orden a través de su plasmación lingüística. Es el carácter linguístico semántico de la historia, en la que los textos, como memoria no hereditaria de una colectividad que toma forma a través de un determinado sistema linguístico, deben entenderse desde el punto de vista axiológico como la plasmación de un sistema de valores.

Por ello, frente a la historia de lo visible «que hay que ver», común a historiadores e intérpretes (principalmente la contemporánea), y a la historia del análisis «que hay que pensar», visible para el historiador y describible para el filólogo formal (la historia como descripción positivista), la historia como interpretación - lingüística- «que hay que vivir» presenta la mirada ideal en el dominio de lo invisible (el ámbito del contenido), con la finalidad de captar - y, por ello mismo, comprender-- las manifestaciones del Espíritu y su actualización a través del sistema linguístico.

\section{Referencias bibliográficas}

Borges Duarte, I. (1995): «¿Recepción o interpretación? Reflejos de la mirada heideggeriana hacia Kant», Anales del Seminario de Historia de la Filosofía, 12, págs. 213-232.

Bravo, J. M. y Schökel, L. A. (1997): Apuntes de hermenéutica, Trotta, Madrid. Burke, P. (ed.) (1993): Formas de hacer Historia, Alianza, Madrid. 
Crespillo, M. (1981): «Predominio lingüistico e interdisciplinariedad», Ciencias y Letras, 3, págs. 25-31.

Cruz, M. (1991): Filosofía de la Historia, Paidós, Barcelona.

Dilthey, W. (1978): El Mundo Histórico, Fondo de Cultura Económica, México.

Domínguez Caparrós, J. (ed.) (1997): Hermenéutica, Arco/Libros, Madrid.

Droysen, J. G. (1983): Histórica. Lecciones sobre la Enciclopedia y metodología de la Historia, Editorial Alfa, Barcelona.

Esteban Ortega, J. (1996): «La revitalización hermenéutico-lingüística de la memoria en H. G. Gadamer y E. Lledó», Pensamiento, 52, págs. 403-428.

Fidalgo, L. (1996): Hermenéutica y existencia humana. El pensamiento de $P$. Ricoeur, Universidad de Valladolid, Valladolid.

Gadamer, H. G. (1991): Verdad y método. Fundamentos de una filosofía hermenéutica, Sígueme, Salamanca.

Garrido Domínguez, A. (1996): «P. Ricoeur: texto e interpretación», Signa, 5, págs. 219-238.

González Wecenslao, J. (ed.) (1996): El objeto de la Historia y la Teoría de la Acción, Publicaciones de la Universidad de La Coruña, La Coruña.

Hegel, G. W. (1974): Lecciones sobre la filosofia de la historia universal, Revista de Occidente, Madrid.

Heidegger, M. (1975): Ser, Verdad y Fundamento, Monte Ávila editores, Caracas. Heidegger, M. (1982): Arte y poesía, Fondo de Cultura Económica, Madrid.

Heidegger, M. (1993): El ser y el tiempo, Fondo de Cultura Económica, Madrid.

Hirsch, E. (1997): «Tres dimensiones de la hermenéutica», apud Domínguez Caparrós, J. (ed.) (1997): 137-158.

Jarque, V. (1994): «La historiografía de la estética (entre la clausura y la dispersión)», Teoría/Crítica, 1, págs. 231-245.

Jiménez Ruiz, J. L. (1996): «El significado en la historia o la historia del significado», apud Llopis, J. y Tornel, J. L. (1996): 9-17.

Jiménez Ruiz, J. L. (1999): Epistemología del lenguaje, Universidad de Alicante, Alicante -en prensa-.

Koselleck, R. y Gadamer, H. G. (1997): Historia y hermenéutica, Introducción de J. L. Villacañas y F. Oncina, Paidós, I.C.E. Universidad Autónoma de Barcelona, Barcelona.

Koselleck, R. (1993): Futuro pasado. Para una semántica de los tiempos históricos, Paidós, Barcelona.

Lledó, E. (1970): Filosofía y Lenguaje, Ariel, Barcelona.

Lledó, E. (1975): Lenguaje e historia, Ariel, Barcelona.

Lledó, E. (1997): «Literatura y crítica filosófica», apud Domínguez Caparrós, J. (ed.) (1997): 21-57. 
Llopis, J. y Tornel, J. L. (1996): Dinamismo lingüístico: la evolución sociolingüistica de la episteme medieval, Editorial Club Universitario, Alicante. López Sáenz, Ma C. (1996): «El sentido de la Historia de la Filosofía para la Filosofía Hermenéutica», Contrastes, 1, págs. 151-172.

López Sáenz, Ma C. (1997): «El paradigma del texto en la Filosofía Hermenéutica», Pensamiento, 53, págs. 215-242.

Lozano, J. (1987): El discurso histórico, Alianza, Madrid.

Massuh, V. (1990): La flecha del tiempo, Edhasa, Barcelona.

Mate, R. (ed.) (1993): Filosofía de la Historia, Trotta, Madrid.

Montanari, M. et alii (1993): Problemas actuales de la Historia, Universidad de Salamanca, Salamanca.

Ortiz Osés, A. (1973): Antropología hermenéutica, Editorial Ricardo Aguilera, Madrid.

Ortiz Osés, A. (1986): La nueva filosofia hermenéutica, Anthropos, Barcelona.

Pomian, K. (1984): L'ordre du temps, Gallimard, París.

Ramos Requejo, R. (1995): «Para una teoría de la interpretación textual: de Gadamer a Habermas», Grial, 33, págs. 61-93.

Revilla Guzmán, C. (1995): «Los límites de la textualidad. Escritura y diálogo en la hermenéutica gadameriana», Anales del Seminario de Metafísica, 29, págs. 171188.

Ruiz Torres, P. (1993): La Historiografía, Marcial Pons, Madrid.

Sánchez Meca, D. (1997): «Comprensión e interpretación de las obras filosóficas», Diálogo filosófico, 37, págs. 41-54.

Santos, G. (1995): «Apunte sobre una lectura 'paradógica' del Anticipo de la compleción», Anales del Seminario de Historia de la Filosofía, 12, págs. 155162.

Szondi, P. (1997): «Introducción a la hermenéutica literaria», apud Domínguez Caparrós, J. (ed.) (1997): 59-74.

Vilana Taix, V. (1995): «La relación lenguaje-mundo en Verdad y método», Studium, 1, págs. 261-271.

White, H. (1978): Retorica e Storia, Guida, Nápoles. 